\title{
IMPLEMENTASI KAIZEN TERHADAP EFISIENSI BIAYA PRODUKSI PT. DASA ANUGERAH SEJATI ASIAN AGRI JAMBI
}

\author{
${ }^{1}$ Yohendry, ${ }^{2}$ Osrita Hapsara, ${ }^{3}$ Yunan Surono \\ ${ }^{1}$ Alumni Program Magister Manajemen FE UNBARI, ${ }^{2}$ Dosen Program Magister \\ Manajemen FE UNBARI, dan ${ }^{3}$ Dosen Program Magister Manajemen FE \\ UNBARI
}

\begin{abstract}
The company through Kaizen costing to eliminate inefficient activity activities that occur in the company's production process Here, it can be seen clearly the role of Kaizen implementation to Efficiency of Production Cost (represented by Production Yield, Labor Cost, Material Cost and Transport Cost). The analytical method used is descriptive analysis to reveal facts of the object researched and SEM Analisys. The results showed that (1) the characteristics of Muda, Mura, and Muri and Efficiency of Production Cost is good; and (2) Implementation of Muda, Mura, and Muri together have a positive and significant effect on Efficiency of Production Cost PT. Dasa Anugerah Sejati - Asian Agri Jambi by 83\%. The remaining $17 \%$ is influenced by other factors not examined. Implementation of Muda, Mura, and Muri have a positive effect on Production Cost Efficiency, meaning that high Efficiency of Production Cost is influenced by high implementation of Muda, Mura, and Muri.
\end{abstract}

Keywords: Kaizen Costing, Efficiency of Production Cost, Production Yield, Labor Cost, Matherial Cost, Transport Cost, Muda, Mura, and Muri

\section{PENDAHULUAN}

Fenomena pertumbuhan ekonomi Jepang paska Perang Dunia II memberikan motivasi pembangunan kembali dari puing peperangan dan diutuslah seorang ahli survey AS yang bernama Dr. W. Edward Deming yang mencoba membantu Jepang untuk pembangunan kembali ekonomi Jepang sehingga konsep Deming mulai tahun 1970-an telah diterapkan oleh perusahaan Jepang yang terkenal dengan "14 kunci Dr. Deming" dan anehnya sukses penerapan konsep Deming di industri jepang pemerintah AS baru tertarik pada konsep tersebut.

Namun konsep Deming yang Kemudian lebih dikenal dengan konsep Kaizen secara luas baru diperkenalkan oleh Masaaki Imai dalam bukunya "Kaizen: the key to Japan's competitive success" (1986). Kesimpulan Europe Japan Centre tentang Kaizen Jepang yang mengungkapkan bahwa: "Kaizen mengatakan kepada kita bahwa hanya dengan secara terus menerus tetap sadar dan membuat beratus-ratus ribu peningkatan kecil, maka dimungkinkan untuk menghasilkan barang dan jasa yang mutunya otentik sehingga memuaskan pelanggan. Cara paling mudah mencapainya adalah dengan keikutsertaan, motivasi dan peningkatan terus menerus dari masing-masing dan semua karyawan dalam organisasi. Keikutsertaan staf tergantung pada komintmen manajemen senior, strategi yang jelas dan ketabahan, karena Kaizen bukan jalan pintas melainkan proses yang berjalan secara terus menerus untuk menciptakan hasil yang diinginkan". (Cane, 1998:265)

Kata Kaizen sebenarnya sudah pernah dijalankan di Cina oleh Dinasti Qing dari tahun 1644 hingga 1911. Pada awal abad ke-20, istilah Kaizen secara bertahap mulai dipublikasi untuk digunakan dalam praktek-praktek kerja di Jepang. 
Persaingan yang sangat tajam terjadi di semua lini usaha dalam era perdagangan bebas. Fakta ini membawa dampak positif dan negatif bagi Indonesia. Adapun dampak positifnya adalah memberikan peluang bagi Indonesia untuk mengekspor produk yang semakin luas. Sedangkan dampak negatifnya adalah persaingan yang terjadi bukan hanya antar pelaku bisnis domestik, tetapi melibatkan pula pelaku bisnis dari luar negeri yang semakin bebas memasarkan produk di Indonesia.

Sejalan dengan perkembangan teknologi dewasa ini, jenis-jenis produk makin bertambah jumlahnya. Seiring dengan itu, persoalan yang dihadapi perusahaan terutama perusahaan industri akan semakin komplek. Hal ini menuntut manajemen perusahaan untuk menentukan suatu tindakan dengan memilih berbagai alternatif dan kebijaksanaan dalam mengambil keputusan yang sebaikbaiknya agar tujuan perusahaan dapat tercapai. Salah satu tujuan yang paling utama adalah optimalisasi laba atau keuntungan.

Perusahaan yang ingin berkembang atau paling tidak bertahan hidup harus mampu menghasilkan produksi yang tinggi dengan kualitas yang baik. Hasil produksi yang tinggi akan tercapai apabila perusahaan memiliki efisiensi produksi yang tinggi. Akan tetapi untuk mencapai efisiensi produksi yang tinggi ini tidak mudah, karena banyak faktor yang mempengaruhinya, baik faktor internal maupun eksternal perusahaan. Faktor-faktor tersebut antara lain tenaga kerja, bahan baku, mesin, metode produksi dan pasar.

Agar dapat bersaing dalam pasaran sekarang, perusahaan harus dapat menciptakan suatu produk baik barang maupun jasa yang harganya lebih rendah atau paling tidak sama dengan harga yang ditawarkan para pesaingnya. Untuk dapat memperoleh produk seperti itu, perusahaan harus berusaha sebisa mungkin mengurangi biaya yang harus dikeluarkan pada proses porduksinya. Salah satu metode yang digunakan oleh perusahaan-perusahaan di Jepang untuk lolos dari keterpurukan setelah kalah perang dan dibom atom setelah perang dunia kedua adalah target costing. Konsep target costing sangat sesuai sejalan dengan meningkatnya persaingan serta tingkat penawaran yang jauh melampaui tingkat permintaan, maka kekuatan pasar memberi pengaruh yang semakin besar terhadap tingkat harga. Untuk itulah diperlukan target costing untuk dapat mencapai tujuan perusahaan dalam rangka pengurangan biaya (cost reduction), yang pada akhirnya akan membawa dampak terhadap tingkat harga yang kompetitif.

Target costing merupakan sebuah perubahan terhadap pola pikir selama ini, serta merupakan kunci jangka panjang bagi kelangsungan hidup, pertumbuhan dan kemakmuran suatu perusahaan dalam lingkungan yan kompetitif dan terus menerus berubah ini. Dengan target costing, perusahaan dapat merancang sebuah produk atau jasa yang dapat memenuhi kebutuhan konsumen sekaligus dapat mencapai target laba perusahaan secara simultan, karena target costing mempertimbangkan seluruh biaya produk dalam siklus hidup produk, dan bertujuan untuk menurunkan biaya total sebuah produk.

Setelah mengetahui target biaya yang harus dikeluarkan agar dapat menghasilkan produk yang dapat bersaing, langkah selanjutnya adalah memproduksi barang atau jasa tersebut. Untuk pelaksanaannya akan lebih baik apabila perusahaan menggunakan metode yang juga berasal dari Jepang yaitu kaizen costing. Kaizen costing adalah konsep perbaikan terus menerus (continuous improvement) dimana disetiap tahap produksi diusahakan adanya perbaikan-perbaikan agar lebih optimal dan efektif, sehingga nantinya akan dapat mengurangi biaya. 
Krisis minyak pada tahun 1970-anlah yang memicu kesabaran pentingnya peranan kaizen dalam berbisnis, dimana pada tahun tersebut membawa perubahan dalam dunia usaha dimana terjadi peningkatan yang tajam pada biaya bahan, energi, dan karyawan; sarana produksi yang melebihi kapasitas; peningkatan persaingan antar perusahaan; perubahan nilai pelanggan yang menuntut mutu lebih baik; dan lain-lain. Perubahan kondisi tersebut segera disikapi oleh orangorang Jepang dengan menggunakan kaizen, sementara dunia Barat masih terbuai oleh inovasi.

Dulu di awal 1970-an, konsumen di AS melecehkan sedan Toyota sebagai mainan, karena bentuknya yang kotak dan ukurannya yang kecil, kalau pun tak dianggap mainan, citranya tak jauh dari Kijang generasi pertama yang bagai kaleng kerupuk, kalah oleh mobil lain bahkan oleh teman Jepang-nya seperti Mitsubishi Colt T120.

Kesuksesannya sekarang pantas dibanggakan dan dirayakan Toyota, karena merupakan hasil kerja berpuluh-puluh tahun dari hanya produsen lokal menjadi perusahaan otomotif terbesar dunia. Menggambarkan kesuksesan Toyota di tataran dunia tidak beda jauh dengan gambaran kisah sukses Kijang yang merebut dan kemudian mendominasi pasar otomotif Indonesia. Padahal kelahirannya di tahun 1930-an justru karena keterpurukan yang dialami keluarga pendirinya, keluarga Toyoda. Kunci dari keberhasilan perusahaan ini mengubah keterpurukan menjadi sukses besar adalah Toyota Production System (TPS), suatu sistem produksi yang dapat dikatakan terbaik karena memiliki efisiensi yang luar biasa.

TPS merupakan cara berpikir Toyota untuk membuat mobil dengan kualitas yang lebih baik, harga reasonable bagi masyarakat luas dan tersedia sesuai permintaan. Filosofi dasarnya adalah kepuasan pelanggan, kualitas bagus, "Kaizen" (perbaikan terus-menerus), dan tidak boros.

Pesatnya perkembangan Toyota sekarang, berkat metode perbaikan dan pengembangan yang terus dijalankan secara konsisten. Salah satu metodenya yang paling mutakhir ialah yang disebut Kaizen Methods, yaitu berupa enam langkah jitu dalam membuat inovasi produk, efisiensi rantai pasokan, dan pelaksanaan manufaktur internal. Pola dasar dari keenam langkah tersebut sebagai berikut: (1) menemukan potensi perbaikan; (2) menganalisis metode yang digunakan saat ini: (3) mencetuskan ide orisinal; (4) menyusun rencana penerapan; (5) menerapkan rencana; dan (6) mengevaluasi metode baru.

Kaizen memiliki inti konsep "bekerja cerdas", bukan "bekerja keras". Misalnya dalam meningkatkan produksi. Di dalam Kaizen tidak perlu menambah waktu dan tenaga kerja, tapi yang dilakukan adalah menghasilkan produk berkualitas layak jual dalam jumlah lebih besar dengan menggunakan tenaga kerja, mesin, dan batasan waktu yang sudah ada. Kaizen sangat meminimalisir pemborosan dalam berbagai sektor. Efisiensi sangat ditekankan sekali dalam proses kerja dalam pelatihan metode Kaizen.

Semua area pemborosan harus diperbaiki agar tercipta kinerja yang efisien, baik dari segi biaya, peralatan, tenaga kerja, manajemen, dan waktu. Kaizen memiliki pola tersendiri untuk mengatasi hal ini. Karenanya, sangat wajar metode Kaizen telah membantu mengangkat kualitas dan kuantitas produksi pabrikan Toyota sehingga mampu memimpin pasar otomotif dunia.

Adapun langkah strategik yang diambil Asian Agri adalah konsep Kaizen atau dalam bahasa Inggris dikenal dengan Continual Improvement. Konsep ini telah lama atau sangat populer di negara Jepang, salah satu perusahaan yang menerapkan konsep ini adalah perusahaan otomotif Toyota. Bisa kita lihat 
bagaimana kekuatan mobil Toyota begitu perkasa ketika terjadi krisis global dan bahkan mengalahkan perusahaan otomotif dunia lainnya seperti General Motors (GM) yang banyak melakukan Pemutusan Hubungan Kerja (PHK) terhadap karyawannya.

Sampai pertengahan tahun 1970-an minyak kelapa merupakan pemasok utama dalam kebutuhan minyak nabati dalam negeri. Baik minyak goreng maupun industri pangan lainnya lebih banyak menggunakan minyak kelapa dari pada minyak sawit. Produksi kelapa yang cenderung menurun selama 20 tahun terakhir ini menyebabkan pasokannya tidak terjamin, sehingga timbul krisis minyak kelapa pada awal tahun 1970. Di sisi lain, produksi minyak kelapa sawit cenderung meningkat sehingga kedudukan minyak kelapa digantikan oleh kelapa sawit, terutama dalam industri minyak goreng. Dari segi perolehan devisa, selama beberapa tahun terkhir ini kondisinya kurang baik. Volume ekspor selama dekade terakhir ini memang selalu meningkat, akan tetapi peningkatannya tidak selalu diikuti oleh peningkatan dalam nilainya. Hal ini terjadi karena adanya fluktuasi harga di pasaran internasional.

Melihat keuntungan besar dan bahkan dikatakan semua bagian dari janjang kelapa sawit yang dipanen bisa dikatakan dapat dipakai semuanya baik untuk makanan, kosmetik dan pupuk. Akibat faktor-faktor inilah, banyak sekali para pengusaha bidang lain beralih ke agrobisnis penanaman dan pengolahan kepala sawit sehingga ketika kondisi sedang peak crop (panen puncak) atau bisa dikatakan kelebihan buah sawit yang dapat mengakibatkan produk minyak sawit berlebih di pasaran dunia. Hal ini membuat harga terkoreksi turun secara drastis, harga akan kembali tinggi apabila kondisi panen mulai stabil atau bahkan pada kondisi low crop (produksi buah sawit turun drastis).

Tabel 1 biaya produksi dan hasil produksi Kebun Taman Raja (KTR) tahun 2007 - 2014 menunjukkan bahwa biaya tenaga kerja (BTK), biaya material (BM), dan biaya transportasi (BT) sangat fluktuatif dan bahkan cenderung naik, sedangkan hasil produksi sangat fluktuatif dan cenderung stagnan dan menurun. Tahun 2007 menunjukkan total biaya produksi Rp. 23.004.123.121,- dan tahun 2014 adanya kenaikan biaya produksi menjadi Rp. 49.164.279.653,-, artinya ada kenaikan biaya sebesar Rp. 26.160.156.532,- atau 113,7\%, sedangkan hasil produksi pada tahun 2007 adalah 72.395,61 ton dan 122.163,03 ton pada tahun 2014 , terjadi kenaikan sebesar $49.767,42$ ton atau $68,7 \%$. Kenaikan biaya produksi jauh lebih besar dibandingkan dengan kenaikan hasil produksi.

\section{Tabel 1}

\section{Biaya Produksi dan Hasil Produksi KTR}

\begin{tabular}{|c|c|c|c|c|r|}
\hline Tahun & $\begin{array}{c}\text { BTK } \\
\text { (Rp.) }\end{array}$ & $\begin{array}{c}\text { BM } \\
(\text { Rp. })\end{array}$ & $\begin{array}{c}\text { BT } \\
(\text { Rp. })\end{array}$ & $\begin{array}{c}\text { Total Biaya } \\
\text { Produksi } \\
(\text { Rp. })\end{array}$ & $\begin{array}{c}\text { Produksi } \\
\text { (Ton) }\end{array}$ \\
\hline \hline 2007 & 11.587 .061 .537 & 8.423 .925 .445 & 2.993 .136 .139 & 23.004 .123 .121 & $72.395,61$ \\
\hline 2008 & 14.025 .169 .610 & 14.930 .647 .147 & 4.239 .395 .812 & 33.195 .212 .569 & $85.207,96$ \\
\hline 2009 & 16.008 .037 .640 & 29.417 .946 .634 & 4.480 .752 .371 & 49.906 .736 .645 & $102.240,00$ \\
\hline 2010 & 16.008 .037 .640 & 29.417 .946 .634 & 4.480 .752 .371 & 49.906 .736 .645 & $97.040,98$ \\
\hline 2011 & 18.805 .839 .064 & 15.199 .644 .242 & 8.236 .283 .784 & 42.241 .767 .090 & $102.321,78$ \\
\hline 2012 & 22.641 .532 .146 & 16.995 .834 .588 & 9.994 .663 .644 & 49.632 .030 .378 & $118.875,19$ \\
\hline 2013 & 21.315 .034 .426 & 18.007 .241 .353 & 8.550 .959 .442 & 47.873 .235 .220 & $107.722,91$ \\
\hline 2014 & 23.294 .350 .296 & 18.884 .177 .517 & 6.985 .751 .840 & 49.164 .279 .653 & $122.163,03$ \\
\hline \hline Total & $\mathbf{1 4 3 . 6 8 5 . 0 6 2 . 3 5 9}$ & $\mathbf{1 5 1 . 2 7 7 . 3 6 3 . 5 6 0}$ & $\mathbf{4 9 . 9 6 1 . 6 9 5 . 4 0 3}$ & $\mathbf{3 4 4 . 9 2 4 . 1 2 1 . 3 2 1}$ & $\mathbf{8 0 7 . 9 6 7 , 4 6}$ \\
\hline
\end{tabular}

BTK = Biaya Tenaga Kerja, BM = Biaya Material, BT = Biaya Transportasi

Sumber : Data Plantation M anagement Sy stem KTR periode 2007 - 2014 
Tabel 2 biaya produksi (Rp./ton, Rp./kg dan Rp/ha) dan produktifitas (ton/ha) Kebun Taman Raja (KTR) tahun 2007 - 2014 menunjukkan bahwa Rp./ton pada 2007 sebesar Rp. 317.755,77/ton dan 2014 sebesar Rp. 402.448,10/ton, terjadi kenaikan biaya sebesar Rp. 84.692,33/ton atau 26,7\%, Rp./ha pada 2007 sebesar Rp.4.767.693,91/ha dan 2014 sebesar Rp. 10.189.488,01/ha, terjadi kenaikan biaya sebesar Rp. 5.421.794,10/ha atau 113,7\%, serta produktifitas (Ton/ha) pada 2007 sebesar 15,00 ton/ha dan 2014 sebesar 25,32 ton/ha, terjadi kenaikan sebesar 10,93 Ton/ha atau 68,8\%. Kenaikan biaya produksi (Rp./ha) jauh lebih besar dibandingkan dengan kenaikan produktifitas (Ton/ha).

Tabel 2

Efisiensi Biaya Produksi (Rp. per ton, Rp. per kg, dan Rp. per ha) dan Produktifitas (ton/ ha) KTR

\begin{tabular}{|c|r|r|r|r|r|r|}
\hline Tahun & $\begin{array}{c}\text { Total } \\
\text { (Rp.) }\end{array}$ & $\begin{array}{c}\text { Produksi } \\
\text { (Ton) }\end{array}$ & \multicolumn{1}{c|}{ Rp/ Ton } & Rp/ Kg & \multicolumn{1}{|c|}{ Rp/ Ha } & Ton/ Ha \\
\hline \hline 2007 & 23.004 .123 .121 & $72.395,61$ & $317.755,77$ & 317,76 & $4.767 .693,91$ & 15,00 \\
\hline 2008 & 33.195 .212 .569 & $85.207,96$ & $389.578,77$ & 389,58 & $6.879 .836,80$ & 17,66 \\
\hline 2009 & 49.906 .736 .645 & $102.240,00$ & $488.133,18$ & 488,13 & $10.343 .365,11$ & 21,19 \\
\hline 2010 & 49.906 .736 .645 & $97.040,98$ & $514.285,17$ & 514,29 & $10.343 .365,11$ & 20,11 \\
\hline 2011 & 42.241 .767 .090 & $102.321,78$ & $412.832,61$ & 412,83 & $8.754 .770,38$ & 21,21 \\
\hline 2012 & 49.632 .030 .378 & $118.875,19$ & $417.513,78$ & 417,51 & $10.286 .431,17$ & 24,64 \\
\hline 2013 & 47.873 .235 .220 & $107.722,91$ & $444.410,90$ & 444,41 & $9.921 .914,04$ & 22,33 \\
\hline 2014 & 49.164 .279 .653 & $122.163,03$ & $402.448,10$ & 402,45 & $10.189 .488,01$ & 25,32 \\
\hline Total & $\mathbf{3 4 4 . 9 2 4 . 1 2 1 . 3 2 1}$ & $\mathbf{8 0 7 . 9 6 7 , 4 6}$ & $\mathbf{4 2 6 . 9 0 3 , 4 8}$ & $\mathbf{4 2 6 , 9 0}$ & $\mathbf{8 . 9 3 5 . 8 5 8 , 0 7}$ & $\mathbf{2 0 , 9 3}$ \\
\hline
\end{tabular}

Sumber : Data Plantation Management Sy stem KTR periode 2007 - 2014

Tabel 3 biaya produksi dan hasil produksi Kebun Badang (KBD) tahun 2007 - 2014 menunjukkan bahwa biaya tenaga kerja (BTK), biaya material (BM), dan biaya transportasi (BT) sangat fluktuatif dan bahkan cenderung naik, sedangkan hasil produksi sangat fluktuatif dan cenderung stagnan dan menurun. Tahun 2007 menunjukkan total biaya produksi Rp. 10.592.994.245,- dan tahun 2014 adanya kenaikan biaya produksi menjadi Rp. 53.562.682.618,-, artinya ada kenaikan biaya sebesar Rp. 42.969.688.373,- atau 405,6\%, sedangkan hasil produksi pada tahun 2007 adalah 35.580,46 ton dan 98.819,55 ton pada tahun 2014, terjadi kenaikan sebesar $63.239,09$ atau $177,7 \%$. Kenaikan biaya produksi jauh lebih besar dibandingkan dengan kenaikan hasil produksi.

Tabel 3

Biaya Produksi dan Hasil Produksi KBD

\begin{tabular}{|l|c|c|c|c|c|}
\hline Tahun & $\begin{array}{c}\text { BTK } \\
\text { (Rp.) }\end{array}$ & $\begin{array}{c}\text { BM } \\
(\text { Rp.) }\end{array}$ & $\begin{array}{c}\text { BT } \\
\text { (Rp.) }\end{array}$ & $\begin{array}{c}\text { Total } \\
(\text { Rp. })\end{array}$ & $\begin{array}{c}\text { Produksi } \\
(\text { Ton) }\end{array}$ \\
\hline \hline 2007 & 5.253 .133 .810 & 3.892 .975 .533 & 1.446 .884 .902 & 10.592 .994 .245 & $35.580,46$ \\
\hline 2008 & 7.376 .997 .061 & 8.294 .965 .343 & 2.170 .631 .583 & 17.842 .593 .987 & $43.066,51$ \\
\hline 2009 & 8.121 .391 .504 & 9.026 .018 .286 & 2.317 .272 .794 & 19.464 .682 .584 & $49.788,37$ \\
\hline 2010 & 13.278 .676 .218 & 15.897 .784 .820 & 3.825 .499 .513 & 33.001 .960 .551 & $53.301,59$ \\
\hline 2011 & 22.488 .719 .794 & 13.530 .672 .944 & 6.583 .496 .774 & 42.602 .889 .512 & $83.227,44$ \\
\hline 2012 & 25.628 .031 .985 & 21.237 .012 .947 & 7.133 .995 .690 & 53.999 .040 .622 & $99.737,91$ \\
\hline 2013 & 24.594 .536 .728 & 16.620 .766 .507 & 5.998 .394 .596 & 47.213 .697 .831 & $88.091,66$ \\
\hline 2014 & 28.176 .463 .893 & 17.353 .917 .071 & 8.032 .301 .654 & 53.562 .682 .618 & $98.819,55$ \\
\hline Total & 134.917.950.993 & $\mathbf{1 0 5 . 8 5 4 . 1 1 3 . 4 5 1}$ & $\mathbf{3 7 . 5 0 8 . 4 7 7 . 5 0 6}$ & $\mathbf{2 7 8 . 2 8 0 . 5 4 1 . 9 5 0}$ & $\mathbf{5 5 1 . 6 1 3 , 4 9}$ \\
\hline BTK = Biaya Tenaga Kerja, BM = Biaya Material, BT = Biaya Transportasi \\
Sumber : Data Plantation Management Sy stem KBD periode 2007 - 2014 \\
\hline
\end{tabular}


Tabel 4 biaya produksi (Rp./ton, Rp./kg dan Rp/ha) dan produktifitas (ton/ha) Kebun Taman Raja tahun 2007 - 2014 menunjukkan bahwa Rp./ton pada 2007 sebesar Rp. 297.719,43/ton dan 2014 sebesar Rp. 542.025,16/ton, terjadi kenaikan biaya sebesar Rp. 244.305,73/ton atau 82,1\%, Rp./ha pada 2007 sebesar Rp. 2.633.762,87/ha dan 2014 sebesar Rp. 13.317.424,82/ha, terjadi kenaikan biaya sebesar Rp. 10.683.661,95/ha atau 405,6\%, serta produktifitas (Ton/ha) pada 2007 sebesar 8,85 ton/ha dan 2014 sebesar 24,57 Ton/ha, terjadi kenaikan sebesar 15,72 ton/ha atau 177,6\%. Kenaikan biaya produksi (Rp./ha) jauh lebih besar dibandingkan dengan kenaikan produktifitas (Ton/ha).

\section{Tabel 4}

Efisiensi Biaya Produksi (Rp. per ton, Rp. per kg, dan Rp. per ha) dan Produktifitas (ton/ ha) Kebun Badang

\begin{tabular}{|c|c|r|r|r|r|r|}
\hline Tahun & $\begin{array}{c}\text { Total } \\
\text { (Rp.) }\end{array}$ & $\begin{array}{c}\text { Produksi } \\
\text { (Ton) }\end{array}$ & \multicolumn{1}{|c|}{ Rp/ Ton } & Rp/ Kg & Rp/ Ha & Ton/ Ha \\
\hline \hline 2007 & 10.592 .994 .245 & $35.580,46$ & $297.719,43$ & 297,72 & $2.633 .762,87$ & 8,85 \\
\hline 2008 & 17.842 .593 .987 & $43.066,51$ & $414.303,23$ & 414,30 & $4.436 .249,13$ & 10,71 \\
\hline 2009 & 19.464 .682 .584 & $49.788,37$ & $390.948,38$ & 390,95 & $4.839 .553,10$ & 12,38 \\
\hline 2010 & 33.001 .960 .551 & $53.301,59$ & $619.155,27$ & 619,16 & $8.205 .360,65$ & 13,25 \\
\hline 2011 & 42.602 .889 .512 & $83.227,44$ & $511.885,14$ & 511,89 & $10.592 .463,83$ & 20,69 \\
\hline 2012 & 53.999 .040 .622 & $99.737,91$ & $541.409,39$ & 541,41 & $13.425 .917,61$ & 24,80 \\
\hline 2013 & 47.213 .697 .831 & $88.091,66$ & $535.961,04$ & 535,96 & $11.738 .860,72$ & 21,90 \\
\hline 2014 & 53.562 .682 .618 & $98.819,55$ & $542.025,16$ & 542,03 & $13.317 .424,82$ & 24,57 \\
\hline Total & $\mathbf{2 7 8 . 2 8 0 . 5 4 1 . 9 5 0}$ & $\mathbf{5 5 1 . 6 1 3 , 4 9}$ & $\mathbf{5 0 4 . 4 8 4 , 6 6}$ & $\mathbf{5 0 4 , 4 8}$ & $\mathbf{8 . 6 4 8 . 6 9 9 , 0 9}$ & $\mathbf{1 7 , 1 4}$ \\
\hline
\end{tabular}

Sumber : Data Plantation Management Sy stem KTR periode 2007 - 2014

Biaya produksi merupakan yang paling utama untuk dipikirkan serta diperhitungkan. Kesalahan perhitungan mampu berakibat fatal bagi kemajuan serta perkembangan perusahaan. Besarnya harga produksi ini akan membuat sebuah perusahaan bisa mengalami kebangkrutan akibat ketidakmampuan perusahaan dalam melakukan manajemen keuangannya.

Biaya produksi adalah biaya-biaya yang dikeluarkan untuk mengolah bahan baku menjadi barang jadi untuk dijual. Dimana biaya produksi ini terdiri dari biaya bahan baku, biaya tenaga kerja langsung, dan biaya overhead pabrik.

Terkadang banyak perusahaan mengurangi mutu kualitas dari produk yang diproduksi hanya untuk mendapatkan biaya produksi yang rendah, namun hal tesebut bukan cara yang tepat untuk membuat biaya produki menjadi lebih rendah, tetapi perusahaan perlu melakukan efisiensi biaya untuk dapat menekan biaya produksi.

Efisiensi biaya produksi adalah hubungan perbandingan antara anggaran biaya produksi (input) dengan realisasi biaya produksi (output). (Syahu Sugian, 2006:76). Untuk menilai efisiensi biaya produksi, secara langsung akan meliputi tiga komponen biaya produksi, yaitu efisiensi biaya bahan baku, efisiensi biaya tenaga kerja langsung, dan efisiensi biaya overhead pabrik. Untuk mengetahui efisien atau tidaknya biaya produksi dilakukan dengan cara menghitung selisih antara anggaran dengan realisasinya.

Efisiensi merupakan suatu hal yang penting yang harus dilakukan oleh perusahaan untuk mencapai laba yang optimal. Konsep efisiensi berkaitan dengan seberapa jauh suatu proses mengkonsumsi masukan dibandingkan dengan standar atau sesuatu yang bisa dijadikan pembanding.

Dalam kondisi seperti ini, perusahaan agrobisnis kelapa sawit sangat memerlukan langkah-langkah strategik agar tetap bisa bersaing ketika harga 
sedang turun dan ditambah dengan kondisi Upah Minimum Propinsi (UMP) setiap tahunnya naik. Tidak menampik kemungkinan hal ini pun terjadi di Perusahaan Kelapa Sawit Asian Group Jambi yang membawahi PT. Inti Indosawit Subur (terletak di Tungkal Ulu dan Muara Bulian), PT. Dasa Anugerah Sejati (terletak di Pelabuhan Dagang, Merlung) dan PT. Rigunas Agri Utama (terletak di Muara Tebo).

Konsep Kaizen yang diterapkan oleh Toyota sangatlah sukses di pasar otomotif dunia. Untuk itu, konsep ini juga diimplementasi oleh Asian Agri Jambi yang mana pertama kali diterapkan di Perkebunan kelapa sawit. Maka dari itu, Peneliti menfokuskan penelitian pada PT. Dasa Anugerah Sejati (PT. DAS) sebagai pilot project konsep Kaizen. PT. DAS ini memiliki 2 unit Kebun dan 1 unit Pabrik, yaitu Kebun Badang, Kebun Taman Raja, dan Pabrik Taman Raja. Lebih spesifik, Peneliti menfokuskan pada unit Kebun Badang dan Kebun Taman Raja. Praktek konsep Kaizen ini yang telah sangat luar biasa diterapkan di perusahaan otomotif dunia dalam memangkas biaya operasional yang tidak perlu dan output produktifitas dapat meningkat tajam. Keberhasilan Toyota ini juga sangat diharapkan dapat terjadi di Perusahaan kelapa sawit Asian Agri Jambi.

Konsep ini dianut oleh Asian Agri dalam memaksimalkan produksi kelapa sawit dan meminimalkan Cost yang sangat berdampak terhadap produktifitas perusahaan kelapa sawit. Sehingga dalam hal ini, Peneliti memandang sangat perlu membagi konsep ini dalam Tesis yang berjudul "Implementasi Kaizen Terhadap Efisiensi Biaya Produksi PT. Dasa Anugerah Sejati - Asian Agri Jambi."

\section{METODE PENELITAN}

Jenis penelitian yang digunakan dalam penelitian ini adalah deskriptif kuantitatif dan metode yang digunakan adalah metode survei deskriptif. Menurut Effendi (2003) dan Ridwan (2010), metode survei deskriptif adalah suatu metode penelitan yang mengambil sampel dari suatu populasi dan menggunakan kuesioner sebagai alat pengumpul data. Dalam penelitian ini, data dan informasi dari responden dengan menggunakan kuesioner. Setelah data diperoleh, kemudian hasilnya akan dipaparkan secara deskriptif dan pada akhir penelitian akan dianalisis untuk menguji hipotesis yang diajukan pada awal penelitian ini.

Dalam Structural Equation Modeling (SEM), ukuran sampel disarankan lebih dari 100 atau minimal 5 kali dari jumlah observasi. Dalam penelitian ini, Peneliti memutuskan untuk menggunakan 120 sampel dari total 210 sampel yang tersedia dengan menggunakan judgement sampling.

Terkait dengan judul penelitian, dimana implementasi Kaizen (Muda, Mura, dan Muri) terhadap efisiensi biaya produksi yang diharapkan dapat memaksimalkan hasil produksi TBS dan meminimalkan biaya produksi (biaya tenaga kerja, biaya material, biaya transportasi) sehingga diharapkan akan meningkatkan produktifitas perusahaan, yang mana variabel penelitiannya terdiri dari: (1) Variabel bebas, terdiri dari Kaizen yang dituangkan dalam konsep Muda, Mura dan Muri; dan (2) Variabel terikat, terdiri dari Efisiensi Biaya produksi yang diwakili oleh hasil produksi TBS dan biaya produksi (operasional) yang diwakili oleh biaya tenaga kerja, biaya material, dan biaya transportasi. 


\section{HASIL DAN PEMBAHASAN}

\section{Uji Statistik Deskriptif}

Uji statistik deskriptif yang dilakukan menunjukkan hasil sebagai berikut:

\begin{tabular}{ccccc}
\hline No. & Variabel & Rentang Skala & Total Skor & Hasil Hipotesis \\
\hline 1 & Muda & $9.792-12.095$ & 11.325 & Baik \\
2 & Mura & $3.672-4.535$ & 4.490 & Baik \\
3 & Muri & $6.120-7.559$ & 7.261 & Baik \\
4 & Efisiensi Biaya Produksi & $4.896-6.047$ & 5.814 & Baik \\
\hline
\end{tabular}

Sumber: Data primer telah diolah melalui software Lisrel 8.70, 2017

Pada tabel di atas terlihat bahwa $M u d a$ berada pada rentang skala baik, Mura berada pada rentang skala baik, dan Muri berada pada rentang skala baik serta Efisiensi Biaya Produksi berada pada rentang skala baik juga.

\section{Uji Statistik Inferensial \& Uji Hipotesis}

Uji statistik inferensial digunakan untuk mengetahui besarnya pengaruh variabel bebas terhadap variabel terikat, sedangkan uji hipotesis melalui uji $\mathrm{F}$ dan uji t digunakan untuk mengetahui signifikansi variabel bebas terhadap variabel terikat.

Hasil pengujian menunjukkan bahwa (1) Implementasi Kaizen (Muda, Mura, dan Muri) secara bersama-sama terhadap Efisiensi Biaya Produksi mempunyai pengaruh positif $83 \%$ dan signifikan baik secara langsung maupun tidak langsung; (2) Implementasi Kaizen (Muda) secara tidak langsung terhadap Efisiensi Biaya Produksi mempunyai pengaruh negatif 18\% dan tidak signifikan; (3) Implementasi Kaizen (Mura) secara tidak langsung terhadap Efisiensi Biaya Produksi mempunyai pengaruh positif 19\% dan signifikan; dan (4) Implementasi Kaizen (Muri) secara tidak langsung terhadap Efisiensi Biaya Produksi mempunyai pengaruh positif $88 \%$ dan signifikan.

Secara simultan (bersama-sama), perusahaan telah dianggap berhasil melakukan implementasi Kaizen dengan cara mengurangi pemborosan, mengurangi ketidakraturan, dan mengurangi beban yang berlebihan yang berimplikasi terhadap efisiensi biaya produksi meningkat (hasil produksi naik, biaya produksi menurun). Meskipun secara parsial, melalui implementasi Mura tidak dapat memberikan pengaruh yang signifikan terhadap efisiensi biaya produksi.

\section{SIMPULAN}

Secara simultan (bersama-sama), perusahaan telah dianggap berhasil melakukan implementasi Kaizen dengan cara mengurangi pemborosan, mengurangi ketidakraturan, dan mengurangi beban yang berlebihan yang berimplikasi terhadap efisiensi biaya produksi meningkat (hasil produksi naik, biaya produksi menurun). Meskipun secara parsial, melalui implementasi Mura tidak dapat memberikan pengaruh yang signifikan terhadap efisiensi biaya produksi.

\section{DAFTAR PUSTAKA}

Alcaraz JLG, Vento MO, Macias AAM, 2017, Kaizen Planning, Implementing and Controlling. Switzerland: Springer International Publishing.

Bukit, Pantun, 2013, Path Analysis, Multivariat dan Non Parametrik. Jambi: Universitas Batanghari.

Davis, Jhon W, 2011, Progressive Kaizen - The Key to Gaining a Global Competitive Advantage, New York: Taylor \& Francis Group. 
Duffy, Grace L, 2014, Modular Kaizen - Continuous and Breakthrough Improvement, Amerika Serikat: ASQ Quality Press Milwaukee, Wisconsin.

Fahmi, Irham, 2012, Pengantar Manajemen Keuangan. Bandung: Penerbit CV. Alfabeta.

Hamel, Mark R, 2010, Kaizen Event Fieldbook - Foundation, Framework, and Standard Work for Effective Events, Amerika Serikat - Michigan: Society of Manufacturing Engineers.

Hariyadi, 2009, Pelatihan Penerapan standar internasional berbasis Quality Management System, Jakarta: Penerbit Nusantara Professional Education.

Hardjosoedarmo, Soewarso, 2004, Total Quality Management. Yogyakarta: Penerbit Andi.

Hasan, M. Iqbal, (2002), Pokok-Pokok Materi Metodologi Penelitian dan Aplikasinya, Indonesia: Ghalia Indonesia.

Hill, Victoria, 2014, A Kaizen Approach to Food Safety - Quality Management in the Value Chain from Wheat to Bread, Switzerland: Springer International Publishing.

Hirano, Hiroyuki, 2005, Penerapan 5S di Tempat Kerja, Jakarta: PQM.

Imai, Masaaki, 1998, Kaizen: Pendekatan Akal Sehat, Berbiaya Rendah pada Manajemen, Jakarta: CV Taruna Grafica. , 2005, Kaizen, Jakarta: PT Pustaka Binaman Pressindo.

Kato I, Smalley A, 2011, Toyota Kaizen Methods - Six Steps to Impovement, New York: Taylor \& Francis Group.

Lareau, William, 2003, Office Kaizen: Transforming Office Operations into a Strategic Competitive Advantage. Amerika Serikat: ASQ Quality Press Milwaukee, Wisconsin.

, 2011, Office Kaizen 2: Harnessing Leadership, Organizations, People, and Tools for Office Excellence. Amerika Serikat: ASQ Quality Press Milwaukee, Wisconsin.

Martin K, Osterling M. 2007, The Kaizen Event Planner - Achieving Rapid Improvement in Office, Service, and Technical Environments, Amerika Serikat - New York: Productivity Press.

Mika, Geoffrey, 2006, Kaizen Event Implementation Manual, Amerika Serikat Michigan: Society of Manufacturing Engineers.

Monden, Yasuhiro, 1995, Sistem Produksi Toyota: Suatu Ancangan Terpadu untuk Penerapan Just in Time (buku pertama), Jakarta: PT Pustaka Binaman Pressindo.

Ortiz, Chris A, 2006, Kaizen Assembly - Designing, Constructing, and Managing a Lean Assembly Line, Kanada: Taylor \& Francis Group.

Pahan, Iyung, 2015, Paduan Teknis Budidaya Kelapa Sawit Untuk Praktisi Perkebunan, Jakarta: Penebar Swadaya.

Pardamean, Maruli, 2017, Kupas Tuntas Agribisnis Kelapa Sawit : Mengelola Kebun dan Pabrik Kelapa Sawit Secara Efektif dan Efisien, Jakarta: Penebar Swadaya.

Prasetyo, Bambang, Arifin, M. Husni, \& Febriana, Enny, 2011, Pengantar Statistik Sosial, Banten: Indonesia Universitas Terbuka.

Sekaran, Uma, 2006, Metode Penelitian Untuk Bisnis. Jakarta: Salemba Empat.

Sonobe T, Otsuka K, 2014, Cluster - Based Industrial Development: Kaizen management for MSE Growth in Developing Countries. Amerika Serikat New York: Palgrave macmillan. 
Stewart, Jhon, 2011, The Toyota Kaizen Continuum - A Practical Guide to Implementing Lean, Amerika Serikat - New York: Taylor \& Francis Group.

Sulastiawan, R. \& Jannah, LM, 2010, Statistik Sosial, Banten: Indonesia Universitas Terbuka.

Wijayanto, Setyo Hari, 2008, Structural Equation Modeling dengan LISREL 8.8: Konsep dan Tutorial, Yogjakarta: Graha Ilmu. 